\title{
Reliability and validity of a new Building Environmental Quality Questionnaire
}

Anson K. C. Chan ${ }^{1}$; Duncan J. Macfarlane ${ }^{1}$; Ester Cerin ${ }^{1}$; Kelvin S. K. Wong ${ }^{2}$; Chris H. F. Ng${ }^{2}$; and Daniel C.W. $\mathrm{Ho}^{2}$

Institute of Human Performance, The University of Hong Kong ${ }^{1}$ Department of Real Estate and Construction, The University of Hong Kong ${ }^{2}$

Running Head: Building Environmental Quality Questionnaire

Word count of abstract: 225

Word count of text: 4547 (includes Tables/Figures, but excludes Abstract \& References)

Word count of text: 3589 (excludes Tables/Figures/Abstract/References)

Keywords: Building Health Hygiene Index (BHHI), Building Environmental Quality Questionnaire (BEQQ), validation, Perceived Environmental Quality.

\section{Address for Correspondence:}

Dr Duncan Macfarlane, Institute of Human Performance, The University of Hong Kong, 111113 Pokfulam Road, HONG KONG.

Email: DJMAC@HKU.HK

$\mathrm{Ph}:+852-28719451$

Fax: $+852-28188042$ 


\title{
Reliability and validity of a new Building Environmental Quality Questionnaire
}

Anson K. C. Chan ${ }^{1}$; Duncan J. Macfarlane' ${ }^{1}$ Ester Cerin ${ }^{1}$; Kelvin S. K. Wong ${ }^{2}$; Chris H. F. Ng${ }^{2}$; and Daniel C.W. $\mathrm{Ho}^{2}$

\begin{abstract}
This study aimed to develop then test the reliability and validity of a new self-report questionnaire method called the Building Environmental Quality Questionnaire (BEQQ) that was designed to assess the perceived environmental quality in residential apartments in Hong Kong. A total of 108 (46 men and 62 women) Chinese-speaking residents, between 16-81 years of age, took part and completed the questionnaire study. The subjects were recruited from 12 different buildings of three distinct quality ratings (low, medium, and high) assigned by the building assessment tool called the Building Health and Hygiene Index (BHHI). The study was evaluated to determine reliability and this was assessed involving 20 of the participants ( $18 \%$ of the total sample size). The BEQQ was found to have good test-retest reliability, with Intra-class Correlation Coefficient (ICC) values typically around 0.70 . The validity testing, also using ICCs, generated moderate to high values for all BEQQ subcategories (the mean value was around 0.80 ), indicating a good consistency among residents living within the same building. Finally, the summary BEQQ scores were significantly correlated (- 0.68) with the BHHI ratings as the criterion standard. It is concluded that this 8dimension instrument would provide a short and efficient questionnaire method to obtain self-reported information to determine the perceived residential building quality. The method was shown to yield adequate reliability and has been validated for use in empirical research.
\end{abstract}




\section{Introduction}

The built environment has the capacity to affect both the indoor and outdoor physical environments (e.g. climatic conditions and indoor/outdoor air quality), as well as the social environment (e.g. community participation, and investment), and hence could affect the health and quality of life of building residents [1]. Although urban planners and building designers have recognized the implications of their work on public health [1-3], it is often events such as the outbreak of the Severe Acute Respiratory Syndrome (SARS) in 2003, that would draw widespread public concern over the health and hygiene conditions of the living environment, particularly in densely populated areas in an apartment block [4]. Incidents such as SARS have drawn attention to what may constitute a building-related illness (BRI) [5]. Another phenomenon, called sick building syndrome (SBS) [6] could also be of concern to residents when there was high incidence of adverse effects reported [7, 8]. SBS has been defined by the Royal Society of Health, as a phenomenon whereby people experience a range of symptoms when in specific buildings. The symptoms are irritation to the eyes, nose, throat and skin, together with headache, lethargy, irritability and lack of concentration. Although present generally in the population, these symptoms are more prevalent in the occupants of some buildings than others, and improve over time when the afflicted person leaves the building concerned. A range of causative factors has been identified but the substantive cause or causes in any particular building cannot be determined without investigation.

BRI can be caused by specific sources, like asbestos, radon, and carbon dioxide, resulting in allergic, respiratory, neurological, and hematologic illnesses. But according to Wong et al [9], the SBS is not necessarily directly related to one specific source, as most of the SBSs are associated with multiple factors such as poor indoor air quality and conditions that may affect the psychological status of the residents. Factors that have been reported to 
contribute to the SBS in residential buildings include living in cold housing, which has been associated with lower general health status and increased use of health services [10]; dilapidated housing with leaking pipes, peeling paint, or cracks and holes in ceilings, which may act as stressors affecting the immune system [11]; plus damp and mouldy living areas, that have been associated with greater anxiety and depression [12].

The assessment of a building's environmental quality is not new, with several well-known and comprehensive building environmental assessment tools developed in the UK [13], the USA [14], and in Hong Kong [15]. Yet, as there remained a perceived need to develop a more rapid and specific assessment of the many environmental factors contributing to the quality of residential buildings in Hong Kong, Ho et al [4] developed a new assessment tool called the building health and hygiene index (BHHI). The BHHI framework has a hierarchical structure as shown in Figure 1. The built environment was conceptualized with two dimensions: (i) The "design" - representing the "hardware" of a building, and these are usually difficult to change once a building has been completed. The "design" was sub-divided into three categories: architecture, building services, and external environment, which were further divided into 16 subcategories. (ii) The "management", which is generally the "software" of the building. These have dynamic characteristics and are relatively easier to change even after a building has been occupied. This aspect of the built environment can be divided into two categories: operations \& maintenance, and building management, leading to 9 further subcategories. Ho et al [4] used an analytical hierarchical process to assess the importance of all the factors involved in the built environment and reported that the design dimension (weight $=53.6$ per cent) was slightly more important than the management dimension (weight $=46.4$ per cent) in determining the overall perception of hygiene, health and wellbeing of a building for occupants. 


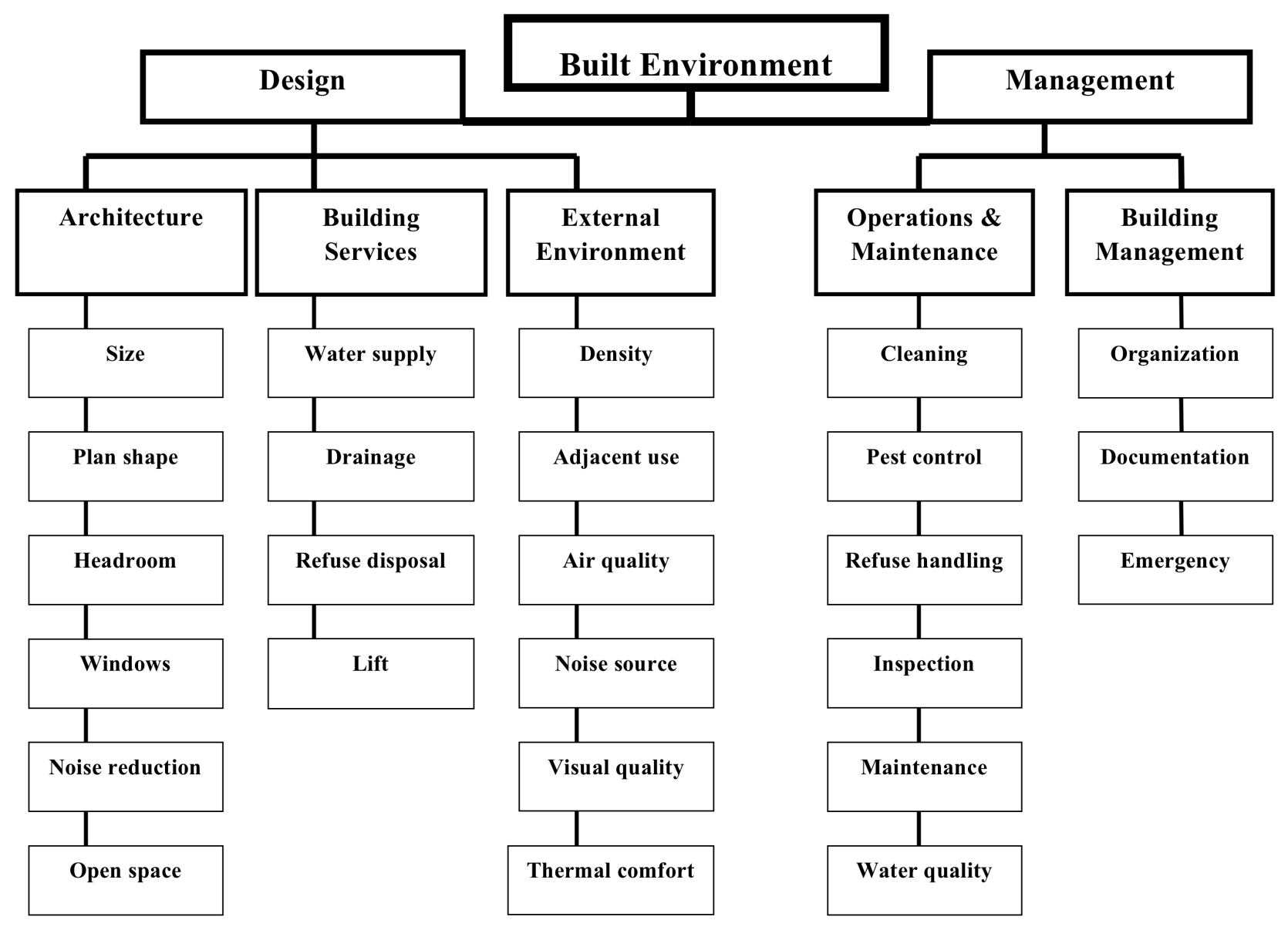

Figure 1: The original BHHI framework

The BHHI has been subsequently applied to rate over 400 residential buildings in Hong Kong, as well as being modified and extended to cover building safety [16]. As suggested by Ho et al [4], the BHHI would be a useful analytical tool for several professional groups in the building sector, especially:

(a) Developers and building owners, as the assessment scheme encourages the construction and maintenance buildings with a due concern of health and wellbeing of occupants;

(b) Architects and designers, as the BHHI provides a useful tool for checking and improving the quality of health and hygiene of new building designs; and 
(c) The government, as the results of the BHHI could be used as one of the criteria for implementing urban renewal and/or mandatory inspection, maintenance and rehabilitation schemes.

Although the BHHI is a good audit tool for grading apartment buildings, there are several practical constraints restricting its widespread use. First, the initial step in constructing the BHHI would require access to the building design information such as building plans, yet these plans may not be available or outdated, particularly for older buildings. Secondly, even if the floor plans are available, the building management corporation may not be cooperative in permitting an inspection of the building conditions or releasing the inspection reports because this would either create an extra workload for the management team, or might even jeopardize renewal of future management contracts if the building is to receive a low BHHI rating, especially in the assessment of the building's management. Finally, the BHHI audit, like other well-known UK, USA and HK building assessments [13-15], would need to be independently conducted by a trained person with a background in architecture, real estate, environmental engineering or construction technology. These limitations would prevent the BHHI being used to collect the extensive amounts of information on the indoor built environment needed for epidemiological public health research.

Owing to these limitations on the BHHI, plus the fact that other public health research has examined the health effects of residential dwellings using self-report questionnaires [17], there is a need for a more cost-effective, questionnaire-based method for the assessment of the environmental quality of buildings that could be completed by residents within the building (either self-completion or by interview). In cooperation with some of the original BHHI research team, a new self-report Building Environmental Quality Questionnaire 
(BEQQ), was designed so that the questionnaire can be completed in less than 10 minutes, but would still address the issues based on the framework of the original BHHI [4], and also a similar questionnaire method introduced by Engvall et al for assessing dwellings in Stockholm [17]. These two studies were chosen to aid the development of BEQQ since the assessment tools are specifically targeted for multifamily residential dwellings, rather than commercial or single residential homes. The main differences between the new BEQQ and the previous Stockholm Indoor Environment Questionnaire (SIEQ) of Engvall et al [17] was that the BEQQ was found to be much more concise (50\% less questions), so as to facilitate high compliance. However, there are important additional questions related to sanitation, tap water quality, and building management practices incorporated in the BEQQ method.

The main objective of designing the BEQQ was to create a very simple and reliable self-reporting questionnaire that would allow assessment of the perceived building environmental quality by the occupants in apartment buildings, which could be validated against the existing quasi-objective criterion BHHI. Such a questionnaire could then be used to investigate the possible associations between the quality of the residential built environment and important issues related to public health (e.g., physical and mental health).

\section{Methods}

We followed the framework of the original BHHI [4] (Figure 1), to develop a tailormade self-report BEQQ suitable to apartment buildings in Hong Kong, with due reference to the Stockholm questionnaire survey method [17]. After identifying what were considered to be the key elements from these two surveys, questionnaire items were developed for the preliminary BEQQ. A series of pilot interviews of residents from the different quality apartment buildings were conducted to examine the acceptability of the preliminary version 
of the BEQQ. Based on the information obtained from the qualitative interviews carried out, the BEQQ was refined. A 5-point Likert-like scale (e.g., 1= very satisfactory; 2= satisfactory, $3=$ unsure; $4=$ unsatisfactory; $5=$ very unsatisfactory), with an additional category for 'no opinion' was provided as response options for the questionnaire items. The BEQQ was originally constructed in English, but underwent a series of forward and backwardtranslations to produce a Chinese version. The procedure included:

(1) A forward translation by a bilingual postgraduate student;

(2) An evaluation of the accuracy of the translated instrument, based on linguistic and psychometric points of view by two independent bilingual experts (English and Cantonese);

(3) Amendments of the first forward translation by the panel of experts;

(4) A back-translation of the BEQQ into English by an independent bilingual translator with no prior background of the research.

These steps were reiterated until equivalence between the original English version and the back-translation of the Chinese version was achieved. 
Figure 2: The BEQQ framework

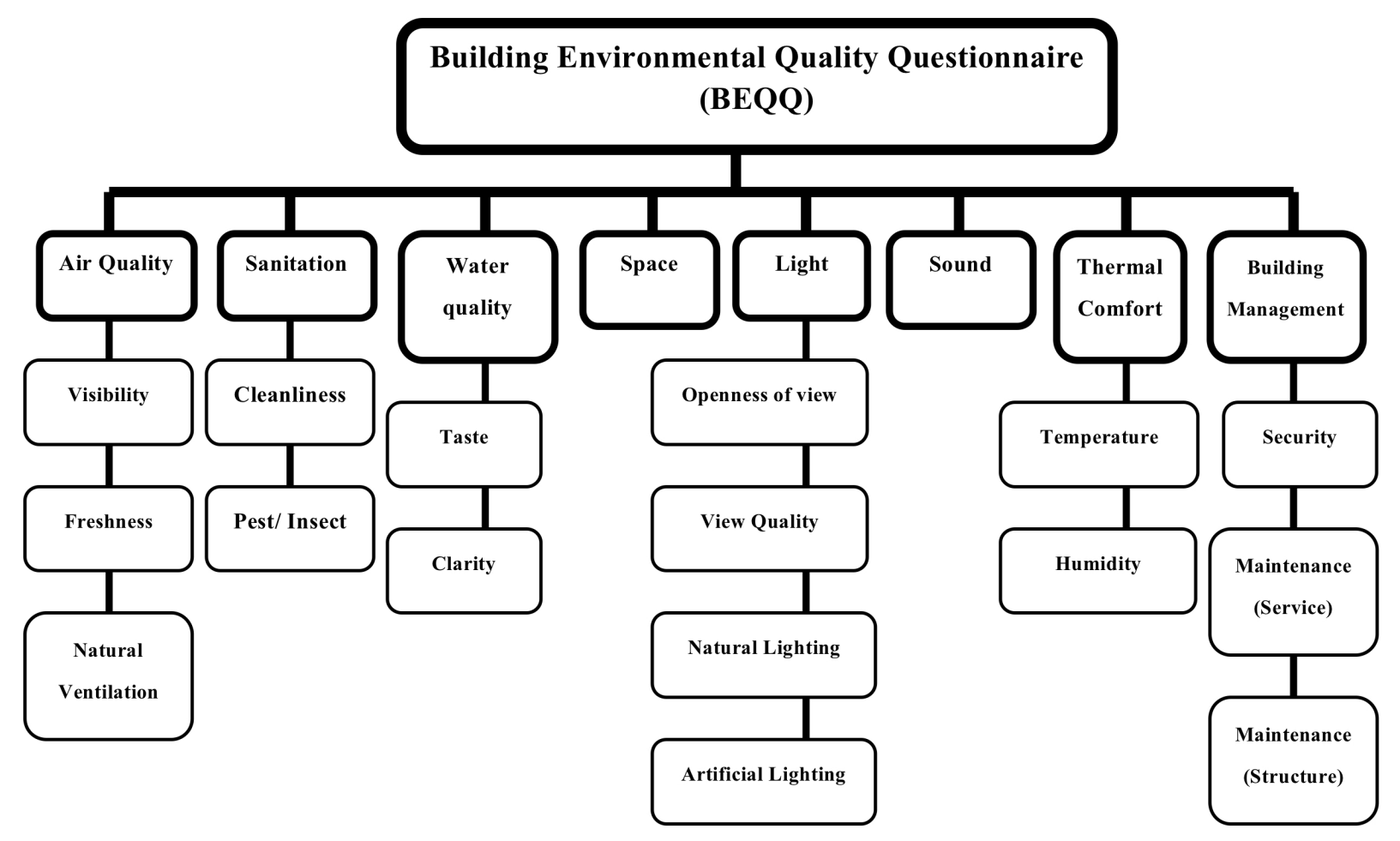

The BEQQ questionnaire was divided into 8 key categories (with sub-items indicated, see Figure 2): Air quality (visibility, freshness, natural ventilation); Sanitation (cleanliness, pest/insect problems); Water quality (taste, clarity); Space; Lighting (openness of view, quality of view, natural lighting, artificial lighting); Acoustic effects (noise levels); Thermal comfort (humidity, temperature); Building management (security level, maintenance of building service, maintenance of building structure and external finishes).

Since some dimensions of the environmental quality might vary across different parts of the building, several of the sub-items (air quality, sanitation, space, lighting, acoustics and thermal comfort) were further categorized into based on the three different areas of the building: (a) within the apartments, (b) common areas shared by residents, and (c) immediate external environment (see Appendix for standard examples of these). Occupants were also 
asked to give an overall rating (the $17^{\text {th }}$ and final question) for the building prior to answering the questions on the basic demographic and household information. A copy of the BEQQ is presented in the Appendix.

The project aimed to interview approximately 120 residents, 10 from each of the 12 selected residential buildings in the Western District of Hong Kong, with 4 buildings chosen to be in each of the high-, medium- and low-grade category according to the BHHI assessment. Figures $3 a, 3 b$, and $3 c$ show a typical example of the low, medium, and high grade buildings as assessed by the BHHI; Table 1 shows the mean descriptive data for the three grades of buildings chosen where there was a clear difference in all variables across the low, medium and high grade buildings.

Table 1: Descriptive data (mean) for the four buildings in the three grades of BHHIdetermined apartment buildings selected for this study. Household data acquired from the Hong Kong Census and Statistics Department[18].

\begin{tabular}{|l|c|c|c|}
\cline { 2 - 4 } \multicolumn{1}{c|}{} & LOW BHHI & MEDIUM BHHI & HIGH BHHI \\
\hline Mean BHHI score & 0.40 & 0.55 & 0.72 \\
\hline Mean construction year & 1989 & 1993 & 1997 \\
\hline Mean floor area (square feet) & 469 & 542 & 1099 \\
\hline $\begin{array}{l}\text { Mean household income } \\
\text { (HK\$ per month) }\end{array}$ & 20,025 & 29,628 & 61,968 \\
\hline Mean rooms per person & 1.2 & 1.4 & 1.5 \\
\hline
\end{tabular}

Figures 3a, 3b, 3c: An example of one of the low (3a), medium (3b), and high (3c) residences graded by the BHHI, showing a wider-angle view of the building and a close-up view of the exterior in each. Note the absence of a balcony and the small window space in the low-grade building; greater window space but no balcony in the middle-grade building; extensive window space and balconies in the high-grade building. 

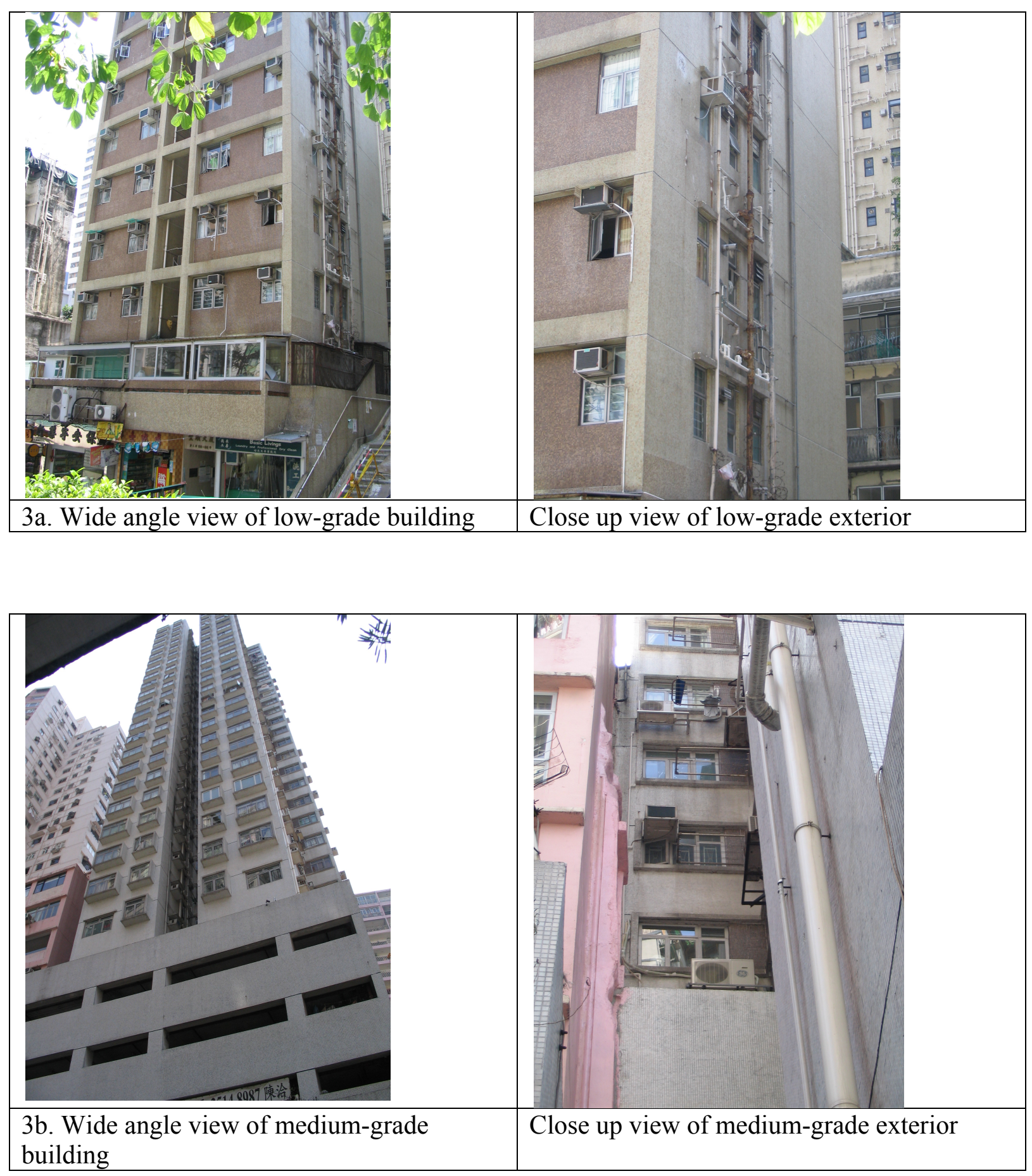


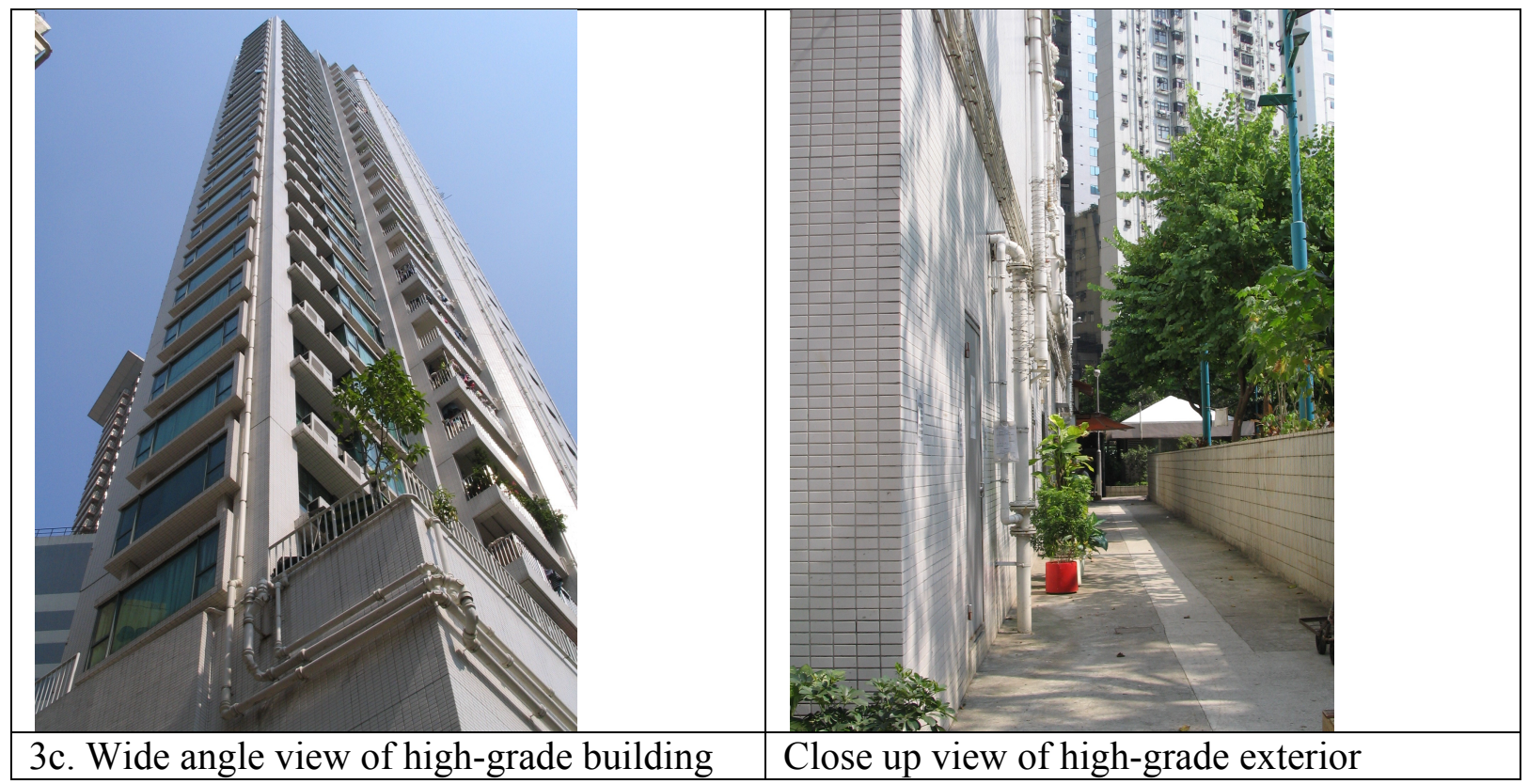


The BHHI grades were not known to the residents at the time of this questionnaire survey, thus they could not have influenced the residents' responses. Eligible participants were Cantonese-speaking residents aged between 16-85 years old, from the selected buildings. They were recruited by random interception as the residents were entering/exiting the building. Participants were asked to complete the BEQQ together with their basic demographic information. A small gift (calculator/clock) was given to each participant after the completion of the interview for their trouble. Potential participants were also asked whether they would be willing to take part in the reliability phase of the study (re-test) that was scheduled 7- 10 days after the first interview. The study was approved by the Research Ethics Committee of the University of Hong Kong.

\section{Data analyses}

The validity of the BEQQ was examined in two ways. First, Pearson correlation coefficients were used to examine the relationship between the BEQQ and the criterion BHHI for the 12 buildings. To do this, the single "overall impression" score (from the final question no. 17), and the summed total of the average score of all categories were used from the BEQQ. Secondly, it was hypothesized that residents living within the same building would report relatively small variations in the BEQQ subscales as compared to much larger variations reported between buildings. Thus, intra-class correlation coefficients (ICCs) were computed to assess how much of the total variance of the subscales could be explained by the between-buildings variance, i.e., the higher the proportion of between-building variance, the higher the degree of consensus between residents and, thus, the objectiveness of their assessment reports. For test-retest reliability, a one-way model single-measure ICC was used to evaluate each of the subscales and the composite average score for each of the categories in the BEQQ. All analyses were performed using SPSS 14.0. 


\section{Results}

A total of 108 participants (46 men and 62 women; mean \pm SD age $=41.8 \pm 13.5$ years old; range 16-81 years old) completed the study. The distribution of respondents in each BHHI building grade was: 39 in low-grade, 34 in medium-grade and 35 in high-grade. Twenty participants took part in the retest component of the study $(18.5 \%$ of the total sample size). The demographic information of the study sample is presented in Table 2.

Table 2: Demographic information of the study participants $(n=108)$ from the three grades of BHHI-determined apartment buildings (numbers shown and percentage in brackets)

\begin{tabular}{|c|c|c|c|c|}
\hline & $\begin{array}{l}\text { LOW } \\
\text { BHHI }\end{array}$ & $\begin{array}{c}\text { MEDIUM } \\
\text { BHHI }\end{array}$ & $\begin{array}{l}\text { HIGH } \\
\text { BHHI }\end{array}$ & OVERALL \\
\hline \multicolumn{5}{|l|}{ GENDER } \\
\hline Male & $18(46.2 \%)$ & $17(50 \%)$ & $11(31.4 \%)$ & $46(42.6 \%)$ \\
\hline \multirow[t]{2}{*}{ Female } & $21(53.8 \%)$ & $17(50 \%)$ & $24(68.6 \%)$ & $62(57.4 \%)$ \\
\hline & & & & $108(100 \%)$ \\
\hline \multicolumn{5}{|l|}{ INCOME (HK\$ per month) } \\
\hline$\leq \$ 5000$ & $1(2.6 \%)$ & $2(5.9 \%)$ & $1(2.9 \%)$ & $4(3.8 \%)$ \\
\hline$\$ 5000-\$ 9999$ & $3(7.9 \%)$ & $0(0.0 \%)$ & $0(0.0 \%)$ & $3(2.8 \%)$ \\
\hline$\$ 10000-\$ 14999$ & $5(13.2 \%)$ & $11(32.4 \%)$ & $0(0.0 \%)$ & $16(15.1 \%)$ \\
\hline \$15 000- \$19 999 & $10(26.3 \%)$ & $2(5.9 \%)$ & $1(2.9 \%)$ & $13(12.3 \%)$ \\
\hline$\$ 20000-\$ 24999$ & $9(23.7 \%)$ & $2(5.9 \%)$ & $2(5.9 \%)$ & $13(12.3 \%)$ \\
\hline$\$ 25000-\$ 29999$ & $5(13.2 \%)$ & $3(8.8 \%)$ & $3(8.8 \%)$ & $11(10.4 \%)$ \\
\hline \multirow[t]{2}{*}{$\geq \$ 30000$} & $5(13.2 \%)$ & $14(41.2 \%)$ & $27(79.4 \%)$ & $46(43.4 \%)$ \\
\hline & & & & $106(98.1 \%)$ \\
\hline \multicolumn{5}{|l|}{ EDUCATION (maximum attained) } \\
\hline Primary school & $8(21.1 \%)$ & $5(14.7 \%)$ & $2(5.7 \%)$ & $15(14 \%)$ \\
\hline $\begin{array}{l}\text { Secondary school (completed Form } \\
5 / \text { Grade10) }\end{array}$ & $10(26.3 \%)$ & $8(23.5 \%)$ & $6(17.1 \%)$ & $24(22.4 \%)$ \\
\hline $\begin{array}{l}\text { High School (completed Form } \\
7 / \text { Grade 12) }\end{array}$ & $9(23.7 \%)$ & $5(14.7 \%)$ & $13(37.1 \%)$ & $27(25.2 \%)$ \\
\hline $\begin{array}{l}\text { College graduate (non-degree, e.g. } \\
\text { Vocational Training School) }\end{array}$ & $3(7.9 \%)$ & $7(20.6 \%)$ & $1(2.9 \%)$ & $11(10.3 \%)$ \\
\hline University (degree) graduate & $6(15.8 \%)$ & $5(14.7 \%)$ & $10(28.6 \%)$ & $21(19.6 \%)$ \\
\hline \multirow[t]{2}{*}{ Postgraduate } & $2(5.3 \%)$ & $4(11.8 \%)$ & $3(8.6 \%)$ & $9(8.4 \%)$ \\
\hline & & & & $107(99.1 \%)$ \\
\hline \multicolumn{5}{|l|}{ AGE (years) } \\
\hline$\leq 18$ & $0(0.0 \%)$ & $0(0.0 \%)$ & $4(11.8 \%)$ & $4(3.8 \%)$ \\
\hline $19-30$ & $9(23.7 \%)$ & $12(35.3 \%)$ & $5(14.7 \%)$ & $26(24.5 \%)$ \\
\hline $31-40$ & $13(34.2 \%)$ & $8(23.5 \%)$ & $8(23.5 \%)$ & $29(27.4 \%)$ \\
\hline $41-50$ & $8(21.1 \%)$ & $9(26.5 \%)$ & $9(26.5 \%)$ & $26(24.5 \%)$ \\
\hline $51-60$ & $7(18.4 \%)$ & $2(5.9 \%)$ & $5(14.7 \%)$ & $14(13.2 \%)$ \\
\hline \multirow[t]{2}{*}{$\geq 61$} & $1(2.6 \%)$ & $3(8.8 \%)$ & $3(8.8 \%)$ & $7(6.6 \%)$ \\
\hline & & & & $106(98.1 \%)$ \\
\hline
\end{tabular}




\begin{tabular}{|l|c|c|c|c|}
\hline RESIDENTAL COMPLEX & & & & \\
\hline FUNG KING COURT & $10(25.6 \%)$ & & & \\
\hline MIDLAND COURT & $12(30.8 \%)$ & & & \\
\hline FOOK MOON BUILDING & $8(20.5 \%)$ & & & \\
\hline YEE SHUN MANSION & $9(23.1 \%)$ & & & $39(36.1 \%)$ \\
\hline BONHAM MANSION & & $9(26.5 \%)$ & & \\
\hline NEW START BUILDING & & $8(23.5 \%)$ & & \\
\hline JADESTONE COURT & & $10(29.4 \%)$ & & \\
\hline HOUSTON COURT & & $7(20.6 \%)$ & & $34(31.4 \%)$ \\
\hline ELITE'S PLACE & & & $11(10.1 \%)$ & \\
\hline PALATIAL CREST & & & $9(8.33 \%)$ & \\
\hline HONOR VILLA & & & $5(4.62 \%)$ & \\
\hline WEALTHY HEIGHTS & $39(36.1 \%)$ & $34(31.4 \%)$ & $35(32.4 \%)$ & $108(10 \%)$ \\
\hline
\end{tabular}

Test-retest reliability for the individual subscales and post-hoc composite average of each category for the BEQQ are shown in Table 3. Nearly all the subscales showed good testretest reliability. The majority of ICCs were approximately 0.70 , and several of the subscales having ICC values greater than 0.90 (all $p$ values $<0.01$ ). Only two of the subscales had ICCs lower than 0.40 (considered to be a marker of poor test-retest reliability; [19]), these were sanitation in external environment and the average score for sanitation.

Table 3: Reliability and validity of the BEQQ.

\begin{tabular}{|c|c|c|c|}
\hline Question & Categories of building environment quality & $\begin{array}{c}\text { Validity } \\
\text { (ICC) }\end{array}$ & $\begin{array}{l}\text { Reliability } \\
\text { (ICC) }\end{array}$ \\
\hline \multirow[t]{2}{*}{1 (a) } & Air Visibility in common area & 0.77 & 0.55 \\
\hline & Air Visibility in external environment & 0.64 & 0.74 \\
\hline \multirow[t]{4}{*}{1 (b) } & Air Visibility in Flat & 0.88 & 0.48 \\
\hline & Air Freshness in common area & 0.82 & 0.66 \\
\hline & Air Freshness in external environment & 0.79 & 0.74 \\
\hline & The Average score of Air* & 0.80 & 0.73 \\
\hline \multirow[t]{4}{*}{$1(\mathrm{c})$} & Ventilation in flat & 0.82 & 0.84 \\
\hline & Ventilation in common area & 0.86 & 0.68 \\
\hline & Ventilation in external environment & 0.74 & 0.78 \\
\hline & The Average score of Ventilation* & 0.83 & 0.87 \\
\hline \multirow[t]{3}{*}{2} & Sanitation in common area & 0.85 & 0.62 \\
\hline & Sanitation in external environment & 0.90 & 0.32 \\
\hline & The Average score of Sanitation* & 0.87 & 0.19 \\
\hline \multirow[t]{3}{*}{3} & Pest Problem in common area & 0.81 & 0.94 \\
\hline & Pest Problem in external environment & 0.77 & 0.86 \\
\hline & The Average score of Pest Problem & 0.79 & 0.93 \\
\hline 4 & Taste of Tap water & 0.89 & 0.57 \\
\hline
\end{tabular}




\begin{tabular}{|c|c|c|c|}
\hline & Clearness of Tap water & 0.91 & 0.54 \\
\hline & The Average score of Tap water* & 0.91 & 0.57 \\
\hline \multirow[t]{4}{*}{5} & Space in flat & 0.90 & 0.61 \\
\hline & Space in common area & 0.94 & 0.85 \\
\hline & Space in external environment & 0.87 & 0.65 \\
\hline & The Average score of Space* & 0.93 & 0.65 \\
\hline 6 & The Openness of external environment & 0.78 & 0.78 \\
\hline 7 & The Quality of external environment & 0.88 & 0.75 \\
\hline \multirow[t]{2}{*}{8} & The Natural lighting in flat & 0.84 & 0.78 \\
\hline & The Natural lighting in common area & 0.88 & 0.71 \\
\hline \multirow[t]{2}{*}{9} & The Artificial lighting in common area & 0.87 & 0.54 \\
\hline & The Average score of Light* & 0.87 & 0.74 \\
\hline \multirow[t]{4}{*}{10} & Noise in the flat & 0.82 & 0.70 \\
\hline & Noise in common area & 0.81 & 0.75 \\
\hline & Noise in external environment & 0.91 & 0.68 \\
\hline & The Average score of Noise* & 0.86 & 0.74 \\
\hline \multirow[t]{3}{*}{11} & Humidity in flat (summer) & 0.66 & 0.59 \\
\hline & Humidity in common area (summer) & 0.85 & 0.73 \\
\hline & Humidity in external environment (summer) & 0.65 & 0.64 \\
\hline \multirow[t]{4}{*}{12} & Humidity in flat (winter) & 0.67 & 0.73 \\
\hline & Humidity in common area (winter) & 0.83 & 0.70 \\
\hline & Humidity in external environment (winter) & 0.81 & 0.66 \\
\hline & The Average score of Humidity* & 0.75 & 0.56 \\
\hline \multirow[t]{3}{*}{13} & Temperature in flat (summer) & 0.92 & 0.82 \\
\hline & Temperature in common area (summer) & 0.95 & 0.66 \\
\hline & Temperature in external environment (summer) & 0.82 & 0.76 \\
\hline \multirow[t]{4}{*}{14} & Temperature in flat (winter) & 0.68 & 0.84 \\
\hline & Temperature in common area (winter) & 0.77 & 0.65 \\
\hline & Temperature in external environment (winter) & 0.78 & 0.81 \\
\hline & The Average score of Temperature* & 0.85 & 0.78 \\
\hline 15 & Security level & 0.88 & 0.65 \\
\hline \multirow[t]{3}{*}{16} & Maintenance of Building & 0.85 & 0.89 \\
\hline & Maintenance of Structure & 0.84 & 0.86 \\
\hline & The Average score of Maintenance* & 0.86 & 0.89 \\
\hline \multirow[t]{2}{*}{17} & Overall Score & 0.93 & 0.61 \\
\hline & Total Average Score of all factors* & 0.91 & 0.87 \\
\hline
\end{tabular}

* = composite (post-hoc) variable (mean of the variables in that category)

Table 3 also shows the result of validity ICC analyses. These ICCs represent the proportion of total variance in the building quality variables due to differences in ratings between residents from different buildings. This measure provides information on the degree of between-resident consensus in ratings of building quality. An ICC of 1.00 indicates that there is no difference in the ratings of residents from the same buildings (i.e., perfect 
consensus between residents). All ICCs were above 0.60 and the average validity ICC was 0.83 , indicating a high degree of agreement in rating between residents of the same buildings.

The criterion validity of the BEQQ was examined by testing the association between the BHHI and BEQQ using Pearson correlation coefficients. The BHHI score of each building was compared with the overall impression score (from question no. 17 in the BEQQ) and the BHHI score was compared with the sum of the averaged BEQQ scores (total of the mean scores in each subscale). A significant correlation coefficient of - 0.68 ( $p \leq 0.014)$, see Figure $4 \& 5$, was found in each analysis showing a high degree of consistency in the results. The negative correlation coefficient was due to the way the BEQQ and BHHI items were scored; in the BEQQ a smaller score denoted higher building quality (i.e., 1 = very satisfactory), whilst in the BHHI a smaller score indicated a lower quality ranking. 
Figure 4: Relationship between BHHI and overall BEQQ score (question no. 17)

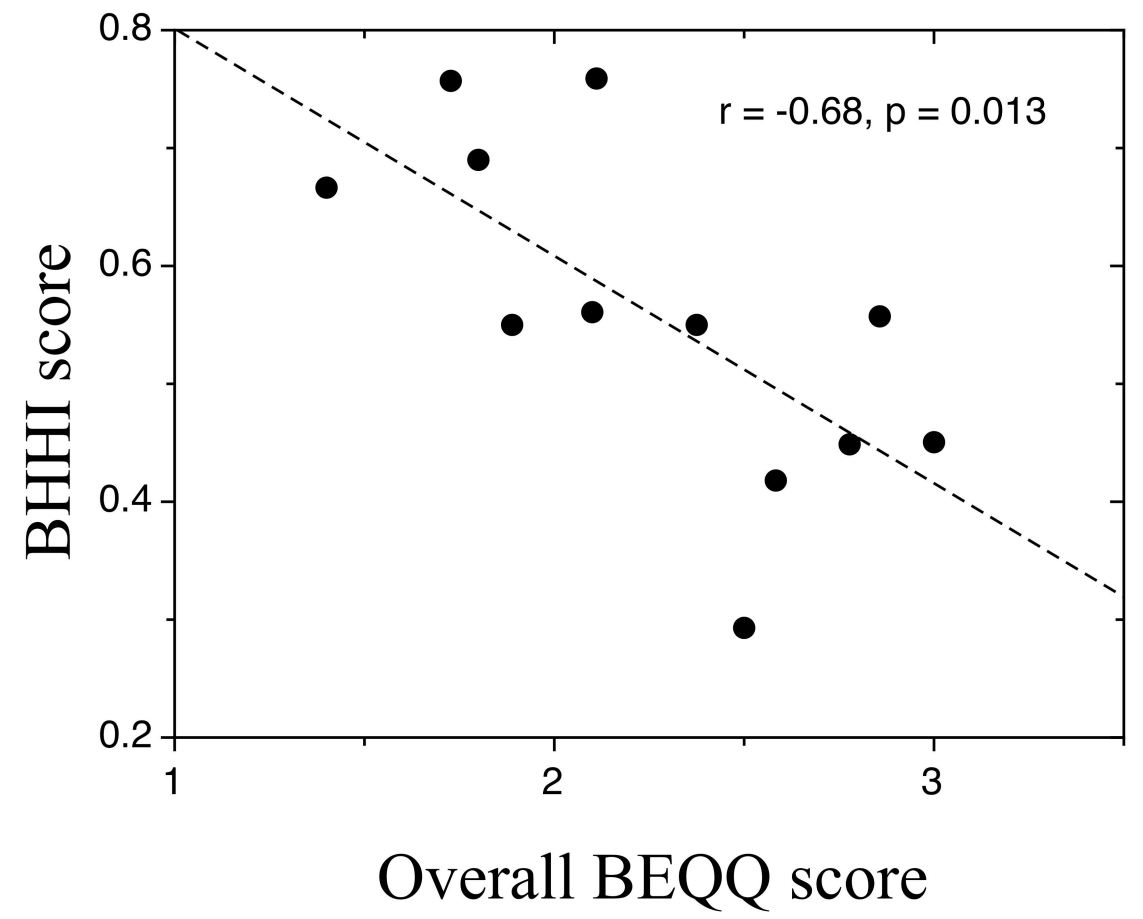

Figure 5: Relationship between BHHI and Total of Averages BEQQ score.

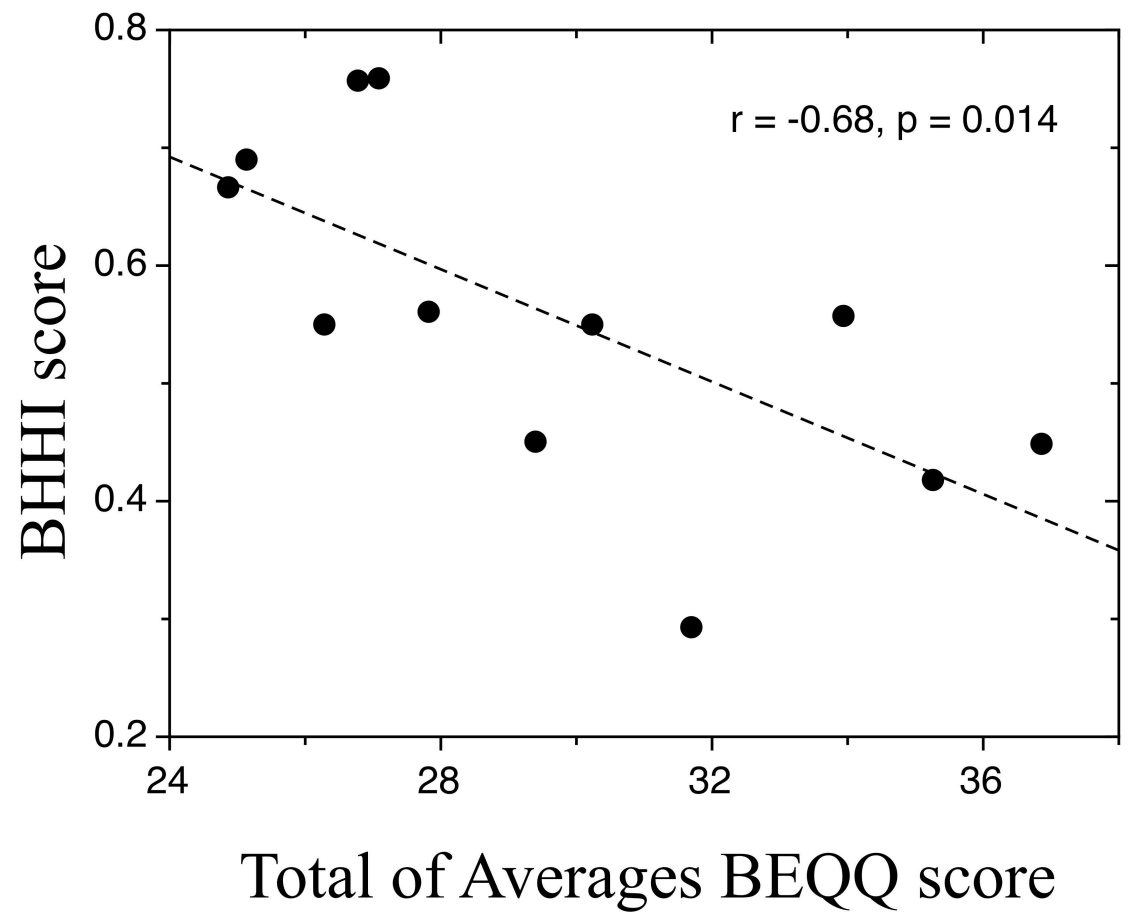




\section{Discussion}

This is a novel study from which a new and rapid self-report questionnaire assessment tool has been developed for the assessment of the perceived built environment of residents living in apartment buildings. The existing standard (BHHI) was used to determine the criterion validity of the BEQQ. A preliminary test of the hypothesis was undertaken to validate and determine the reliability of the information provided by the BEQQ could be obtained based on the occupants' perception using a short self-report questionnaire covering the 8 key categories. Although the ratings from the BEQQ were not designed to replace the BHHI, the self-report perceptions acquired by BEQQ could act as a complementary tool to the more objective, but very labour-intensive, measurements as required by the BHHI. Overall, the respondents, who varied markedly in age and in educational background, had very few difficulties in understanding and completing the BEQQ in 6-8 minutes (this included 36\% who had not been educated beyond Form 5/Grade 10 schooling, and 14\% had not received secondary school education).

The results of the test-retest reliability of the individual BEQQ questions were generally very good, with ICCs ranging from 0.32- 0.94, and only one individual question yielding an ICC below 0.40 (Sanitation in the external areas), as well as only one post-hoc composite (average) score (Overall Sanitation). It was not unexpected that the reliability of certain aspects would be mediocre since the perceived quality of some environmental factors may change over short periods of time. Indeed external sanitation may vary depending on how regularly the apartment residence is cleaned by the management contractors. 
That none of the validity ICCs values were below 0.60 showed that the residents living within the same building generally reported very similar perceived qualities across the full range of variables. This consistency of reporting among residents across each variable has lent some support to the evidence that BEQQ has an element of convergent validity. Although more than half of the validity ICCs were above 0.80 , several of the questions pertaining to perceived humidity came close to the 0.60 value. This slightly lower value of agreement between the residents of the same building regarding perceived humidity was likely due to the differential usage of either dehumidifiers or air-conditioners within each flat/apartment of the residents and therefore would not expect to have a high level of consistency throughout the entire building.

Similarly, the validity of the perceived air visibility of the external environment was somewhat low (0.63) and this may be due to the wide, daily fluctuations in Hong Kong's air quality and although the respondents living in the same building, they were not always interviewed on the same day.

The acceptable Pearson correlations of - 0.68 showed good correlations between the criterion BHHI scores and both the total averages of the BEQQ, as well as the single overall impression score. The results indicated that the BEQQ had statistically significant criterion validity. Although there is no widely accepted, or totally objective "gold standard" for assessing the quality of a building's environment related to its health and hygiene, the BHHI would present an acceptable and reliable criterion even though some questions of the BHHI were based on subjective evaluations. 
This study has a number of limitations. The BEQQ was only designed to suit Hong Kong apartment buildings, although it may also be suitable for other high-density dwellings in other Asian cities. However, it may not be directly suitable to low-density residences found in many other countries, although it has the potential to be easily modified for other urban dwellings.

Although an acceptable number of residents were recruited for the study $(n=108)$, they resided in a limited number of apartment buildings $(n=12)$, thus providing a relatively small number of datum points for the criterion validity analyses, yet the correlations remained statistically significant. A limited number of questions had poor $(\mathrm{ICC}<0.40)$ to moderate (ICC: 0.40 - 0.60) reliabilities and although the overall BEQQ was adequately reliable, some care would need to be taken when interpreting specific results from these less reliable questions. That a few subcategories had low validity ICC values may partially reflect a weakness in the sampling process. Since residents of the same building were not necessarily interviewed on the same day, some variation in climatic conditions may have occurred which could have contributed to greater variations in the perceived environment. All our respondents were interviewed face-to-face and it is unknown if the BEQQ would present the same acceptable levels of validity and reliability if administered via telephone or via selfcompleted questionnaires.

In spite of these limitations, the BEQQ provides a new, rapid, and inexpensive instrument to collate data on the perceived environmental quality of apartment buildings, but should not be used to equate with or replace the more substantive and objective data from the BHHI. However, data from the BEQQ may be easily acquired from large samples in order to compare the perceived quality of the residential environment across districts within a city, 
across cities or even countries. It also opens up opportunities to investigate how the quality of the home environment would contribute to public health (both physical and mental health).

Recently, the role of the environment in health-related research has received considerable attention, but has focused heavily on the influence of the external or neighbourhood built environment [20-22]. Fewer studies have attempted to examine how the quality of the indoor built environment can be related to the occupants' health; hence this new development of the self-report BEQQ may help address this area. Moreover, the BEQQ may play an important role in being able to easily quantify the quality of the environment within a residential complex, as well as to highlight its perceived strengths and weaknesses across the 8 key categories. Such knowledge may be of use not only to the developers, sales agents, building managers, or government officials, but also to provide empirical evidence on what changes, have occurred over time, to a residential complex (e.g., as a result of scheduled maintenance or larger urban renewal programs). The development and implementation of the BEQQ may also facilitate the creation of communities that are more conscious of environmental health concerns as this would require partnership and collaboration amongst the policymakers, governments, researchers, communities, and health specialists with interdisciplinary skills [1].

\section{Conclusion}

It is concluded that BEQQ is a rapid, valid and reliable self-report questionnaire method that can be used to estimate the indoor environmental quality of apartment buildings as perceived by residents. This study has provided and established a way, not only to examine the relationship between the indoor environment and the health of its residents, but also to 
rapidly grade the quality of the residential environment in apartment buildings and to quantify any changes in quality that may occur over time.

Acknowledgement: This study was funded by the University of Hong Kong's URC Strategic Research Theme in Public Health.

\section{References:}

1. Srinivasan S, O'Fallon LR, Dearry A: Creating healthy communities, healthy homes, healthy people: initiating a research agenda on the built environment and public health: Am J Public Health 2003;93:1446-1450.

2. Rousseau D, Wasley J: Healthy by design: building and remodeling solutions for creating healthy homes. Point Roberts, Wash, Hartley \& Marks, 1997.

3. O'Reilly JT: Keeping buildings healthy: how to monitor and prevent indoor environmental problems. New York, J. Wiley, 1998.

4. Ho DCW, Leung HF, Wong SK, Cheung AKC, Lau SSY, Wong WS, Lung DPY, Chau KW: Assessing the health and hygiene performance of apartment buildings: Facilities 2004;22:58-69.

5. Menzies D, Bourbeau J: Building-related illnesses: N Engl J Med 1997;337:15241531. 
6. Raw GJ. A questionnaire for studies of sick building syndrome. A report to The Royal Society of Health Advisory Group on sick building syndrome. In: Raw GJ, ed. Building Research Establishment Report (1). London: Construction Research Communications Ltd; 1995:1-9.

7. Singh J, Yu CWF, Kim JT: Building Pathology, Investigation of Sick Buildings Toxic Moulds: Indoor Built Environ 2010;19:40-47.

8. Yu CWF, Kim JT: Building Pathology, Investigation of Sick Buildings - VOC emissions: Indoor Built Environ 2010;19:30-39.

9. Wong SK, Lai LWC, Ho DCW, Chau KW, Lam CLK, Ng HF: Sick Building Syndrome and perceived indoor environmental quality: a survey of apartment buildings in Hong Kong: Habitat Int 2009;33:463-471.

10. Evans J, Hyndman S, Stewart-Brown S, Smith D, Petersen S: An epidemiological study of the relative importance of damp housing in relation to adult health: J Epidemiol Community Health 2000;54:677-686.

11. Rauh VA, Chew GR, Garfinkel RS: Deteriorated housing contributes to high cockroach allergen levels in inner-city households: Environ Health Perspect 2002;110 Suppl $2: 323-327$

12. Hyndman SJ: Housing dampness and health amongst British Bengalis in east London: Soc Sci Med 1990;30:131-141. 
13. Building Research Establishment Environmental Assessment Method (BREEAM).

Building Research Establishment, 2009. (Accessed January 12, 2009, at

http://www.breeam.org.)

14. Leadership in Energy and Environmental Design (LEED). U.S. Green Building

Council, 2009. (Accessed January 12, 2009, at http://www.usgbc.org.)

15. HK-BEAM: Hong Kong Building Environment Assessment Method (Existing

Buildings). Kowloon, Hong Kong, HK-Beam Society, 2004.

16. Ho DCW, Chau KW, Cheung AKC, Yau Y, Wong SK, Leung HF, Lau SSY, Wong

WS: A survey of the health and safety conditions of apartment buildings in Hong Kong:

Build Environ 2008;43:764-775.

17. Engvall K, Norrby C, Sandstedt E: The Stockholm Indoor Environment Questionnaire:

a sociologically based tool for the assessment of indoor environment and health in dwellings:

Indoor Air 2004; 14:24-33.

18. Centamap. 2009. (Accessed January 11, 2009, at http://www.centamap.com.)

19. Saelens BE, Frank LD, Auffrey C, Whitaker RC, Burdette HL, Colabianchi N:

Measuring Physical Environments of Parks and Playgrounds: EAPRS Instrument

Development and Inter-Rater Reliability: J Phys Act Health 2006;3 (Suppl. 1):S190-S207.

20. Frank LD, Sallis JF, Conway TL, Chapman JE, Saelens BE, Bachman W: Many

pathways from land use to health: J Am Plann Assoc 2006;72:75-87. 
21. Saelens BE, Sallis JF, Black JB, Chen D: Neighborhood-based differences in physical activity: an environment scale evaluation: Am J Public Health 2003;93:1552-1558.

22. Spence JC, Cutumisu N, Edwards J, Evans J: Influence of neighbourhood design and access to facilities on overweight among preschool children: Int J Pediatr Obes 2008;3:109116. 
(Appendix) Building Environmental Quality Questionnaire

This interview is completely voluntary - if we should come to any question that you don't want to answer, just let us know and we'll go to the next question.

DIRECTIONS: The purpose of this questionnaire is to obtain your opinions on the environmental quality of your building, which is typically divided into three parts:

(1) Your flat/apartment;

(2) Common area (e.g. lift lobbies, lifts, and staircases); and

(3) External environment (e.g. podiums, surrounding streets/lanes, and the immediate neighborhood of your building)

Please indicate your opinions by ticking the most suitable boxes.

\section{Air quality}

1. How would you rate the air quality in terms of:

$\begin{aligned} & \text { Very Good Average Poor } \\ & \text { good }\end{aligned} \quad \begin{aligned} & \text { Very } \\ & \text { poor }\end{aligned}$ N/A or
No comment

(a) visibility

in the common area:

in the external environment:

(b) freshness

in your flat:

in the common area:

in the external environment:

(c) natural ventilation

in your flat:

in the common area:

in the external environment:

Sanitation

2. How would you rate the cleanliness:

in the common area:

Very Good Average Poor Very N/A or

good poor No comment

in the external environment:

$\square \quad \square \quad \square$

$\square \quad \square$

3. How would you rate the pest/insect problem in the following areas:

\begin{tabular}{|c|c|c|c|c|}
\hline $\begin{array}{c}\text { No } \\
\text { problem }\end{array}$ & $\begin{array}{c}\text { Minor } \\
\text { problem }\end{array}$ & Average & $\begin{array}{l}\text { Significant } \\
\text { problem }\end{array}$ & $\begin{array}{c}\text { Very } \\
\text { serious } \\
\text { problem }\end{array}$ \\
\hline
\end{tabular}

in the common area:

in the external

environment: 


\section{Water quality}

4. Are you satisfied with the tap water quality (without using filters) in terms of:

$\begin{array}{ccccc}\begin{array}{c}\text { Very } \\ \text { satisfied }\end{array} & \text { Satisfied Average } & \text { Dissatisfied } & \begin{array}{c}\text { Very } \\ \text { dissatisfied }\end{array} & \begin{array}{c}\text { N/A or } \\ \text { No comment }\end{array}\end{array}$

taste:

clarity:

Space

5. Are you satisfied with the amount of space per person in :

Very Satisfied Average Dissatisfied Very N/A or satisfied
your flat:
the common area:
the external
environment:

\section{Light}

6. How would you rate the openness of

7. How would you rate the quality of the

8. How would you rate the natural lighting

9. How would you rate the artificial

\section{Sound}

10. Are you satisfied with the

dissatisfied No comment

$\begin{array}{ll}\square & \square \\ \square & \square \\ \square & \square\end{array}$
the view from your flat? view (e.g. sea view, mountain view, park view, factory view etc.) from your flat? conditions:

in your flat:

in the common area:

lighting conditions (e.g. from

fluorescent tubes and light bulbs):

in the common area:

$$
\text { Very }
$$

Satisfied Average satisfied

Very Good Average Poor Very N/A or

good poor No comment

$\square \quad \square$

$\square$

$\square \quad \square$

$\square$

$\square$

level of noise:

in your flat:

in the common area:

in the external

environment: 


\section{Thermal comfort}

11. Are you satisfied with Very Satisfied Average Dissatisfied Very N/A or satisfied dissatisfied No comment

the humidity level

(without using airconditioning) in

summer:

in your flat:

in the common area:

in the external

environment:

12. Are you satisfied with the humidity level

(without using airconditioning) in winter: in your flat:

in the common area:

in the external

environment:

13. Are you satisfied with the air temperature (without using airconditioning) in summer:

in your flat:

in the common area:

in the external

environment:

14. Are you satisfied with the air temperature (without using airconditioning) in winter: in your flat:

in the common area:

in the external

environment:

\section{Building management}

15. How would you rate the security level of the building? 
16. What is your general opinion of the maintenance of the following:

$\begin{array}{lcccccc} & \begin{array}{c}\text { Very } \\ \text { good }\end{array} & \text { Good } & \text { Average } & \text { Poor } & \begin{array}{c}\text { Very } \\ \text { poor }\end{array} & \begin{array}{c}\text { N/A or } \\ \text { No comment }\end{array} \\ \begin{array}{l}\text { building services (e.g. lifts, } \\ \text { staircases, drainage system): }\end{array} & \square & \square & \square & \square & \square & \square \\ \begin{array}{l}\text { Structure and external } \\ \text { finishes: }\end{array} & \square & \square & \square & \square & \square & \square\end{array}$

\section{Overall}

17. How would you rate the overall

Very Good Average Poor Very $\begin{gathered}\text { N/A or } \\ \text { good No comment }\end{gathered}$
poor
environmental quality of your building? 